\title{
LA IGLESIA DE LOS SANTOS ILDEFONSO Y TOMÁS DE VILLANUEVA EN ROMA: UN MONUMENTO BARROCO A LA PIETAS HISPANICA
}

\author{
Pablo GonzÁlez ToRnel \\ Universitat Jaume I, Castelló
}

En 1667 se pone la primera piedra del Hospicio de los santos Ildefonso y Tomás de Villanueva en la Via Sistina romana. La sede de la orden de los agustinos recoletos en Roma toma una particular configuración arquitectónica, directamente inspirada en la Capilla de los Reyes Magos de Francesco Borromini, y una muy definida iconografía vinculada con la situación política de la segunda mitad del siglo XVII. Así, la iglesia se erige en un monumento a la Inmaculada Concepción concretado en las imágenes de la letanía lauretana que ornan sus muros y reforzado por las pinturas de las vírgenes de Copacabana y Guadalupe en su interior. Todo ello, junto a la advocación a Santo Tomás de Villanueva, canonizado en 1658, convierte el templo en un alegato a la pietas hispanica en un área de la ciudad que fue escenario de los enfrentamientos entre Francia y España.

Palabras clave: Inmaculada Concepción; Roma; Agustinos; Barroco; Pietas hispanica.

\section{THE CHURCH OF SAINTS ILDEFONSO AND TOMÁS DE VILLANUEVA IN ROME: A BARO- QUE MONUMENT TO PIETAS HISPANICA}

In 1667 the construction of the Hospice of Saints Ildefonso and Tomás de Villanueva began on the Roman Via Sistina. The headquarters of the Augustinian Recollects in Rome took on a particular architectural configuration directly inspired by Francesco Borromini's Chapel of the Three Kings and a very concrete iconography linked to the political situation during the second half of the 17th century. Thus the church was decorated to create a monument to the Immaculate Conception with images of the Loreto litany adorning its walls, reinforced by paintings of the Virgins of Copacabana and Guadalupe inside. All of this, combined with the dedication of the building to Saint Tomás de Villanueva (canonized in 1658), turns the temple into a celebration of the pietas hispanica in an area of the Holy City scene of clashes for power between France and Spain.

Key words: Immaculate Conception; Rome; Augustinians; Baroque; Pietas hispanica.

En Roma, con fachada a la Via Sistina, apenas en las estribaciones de la colina del Pincio, se alza la que fue la primera sede de los agustinos recoletos en Roma. El edificio, compuesto por el templo dedicado a los santos Ildefonso y Tomás de Villanueva y la casa anexa, corresponde a una fundación del siglo XVII alimentada por unos contenidos arquitectónicos e iconográficos muy concretos que las pérdidas sufridas durante el gobierno napoleónico y las intervenciones efectuadas durante los siglos XIX y XX no han conseguido ocultar. Se conserva, de este modo, casi oculto 
entre las edificaciones residenciales que lo rodean, un fósil barroco de la política artística de una orden netamente hispana que recuerda los siglos en los que Roma funcionaba como gran teatro del mundo ${ }^{1}$.

La Recolección agustina consigue, no sin problemas, fundar una sede en Roma en el año 1619 gracias a la aprobación del Papa Pablo V y se instala en un solar de la entonces casi deshabitada Strada Felice, abierta solo unos años antes gracias a la intervención de Domenico Fontana por voluntad de Sixto V para unir la basílica de Santa María la Mayor con el poblado Campo de Marte, llegando hasta la fachada del convento de mínimos de la Trinidad. Este eje urbano, destinado a unir las grandes basílicas con el centro habitado, se convertiría en los siglos del Barroco en un área de vital importancia dentro de la ciudad marcado por el cruce casi ortogonal con la Via del Quirinal y por la residencia papal del mismo nombre.

El asentamiento de los agustinos debió ser en sus orígenes tremendamente modesto y solo en 1629 Urbano VIII concede a la fundación la posibilidad de tener el Santísimo Sacramento en el Hospicio, constando que en este momento recibe el nombre de San Guillermo. Durante estos años la relación con la casa madrileña parece fluida y en 1628 se envían desde Roma una serie de cuadros con historias de San Guillermo. En 1655 el agustino peruano Miguel de Aguirre, tras pasar por España, dona en Roma a la incipiente casa de la orden una imagen de la Virgen de Copacabana que adquirirá una enorme importancia para la Recolección romana en los años siguientes. El Hospicio, que ya en 1656 recibe el nombre de San Ildefonso y San Guillermo, recibe en 1657 permiso de Alejandro VII para construir o ampliar su iglesia, aunque durante años la oposición del templo trinitario de Santa Francesca paralizaría la operación. En 1667, finalmente, comienza la construcción del templo actual dedicado ya a San Ildefonso y Santo Tomás de Villanueva, arzobispo de Valencia y agustino canonizado en 1658, según las trazas del arquitecto dominico Giuseppe Paglia $^{2}$. Los destajistas que llevarían a cabo la ejecución de la obra serían los maestros Antonio Cantalupo y sus hijos Giovanni y Andrea y en la piedra fundacional del templo se inscribieron los nombres del Papa Clemente IX y del rey Carlos II (fig. 1).

El 18 de enero de 1672 se bendice solemnemente la nueva iglesia agustina en forma de aula rectangular con dos capillas por flanco, tribunas sobre las mismas y presbiterio cuadrado, toda ella ornada con estucos de los hermanos Antonio y Carlo Cometti. En los paños entre las capillas se colocarían, en fecha incierta y dentro de hornacinas, en el lado de la Epístola, las esculturas de estuco de Santa Rita, San Fulgencio y San Fernando rey de España, y en el lado del Evangelio las de Santa Clara de Montefalco, San Alipio y San Luís rey de Francia. El altar mayor lo ocuparía la imagen de la Virgen de Copacabana traída a Roma por el padre Aguirre, de perfil recortado y pintada sobre tabla, adscrita, aunque sin confirmación documental, al pintor Placido Siculo. En el lado de la Epístola las capillas de dedican a San José, con gran altar marmóreo de Francesco Grassia, único documentado del conjunto agustino ${ }^{3}$, y a San Agustín y Santa Mónica, presidida por un cuadro de los titulares con la Virgen. En el lado del Evangelio la primera capilla a los pies la preside la Virgen de Guadalupe, con cinco pinturas que las crónicas atribuyen al pintor Juan Correa de Murcia, y la segunda se dedicaría a los titulares San Ildefonso y Santo Tomás de Villanueva con

\footnotetext{
${ }^{1}$ Las notas históricas de la fundación provienen de una serie de documentos manuscritos o mecanografiados contenidos en el Archivo General de la Orden de los Agustinos Recoletos (AGOAR), Hospicio de Sant'Ildefonso, Caja 21. El más completo de los escritos es un manuscrito, en el Legajo 2, titulado Apuntes cronológicos del Hospicio de San Ildefonso que recoge año por año las noticias que interesan a la fundación. Apuntes manuscritos extraídos del libro Lumen Domus se encuentran recopilados en la Caja 10, Legajo 2. Véase también Martínez Cuesta, 1995: 306-308. Sobre el devenir contemporáneo de la fundación véase Millán, 1987: 119-149. Véase también Vichi, 1966: 34.

${ }^{2}$ Forte, 1963: 281-409.

${ }^{3}$ Meleo, Mascia, y Curzietti, 2006: 77-87. Sobre este escultor véanse, además, Lopresti, 1927: 89-96. Faldi, 1983 : 126-134.
}

Arch. esp. arte, LXXXVIII, 349, ENERO-MARZO 2015, 69-84 ISSN: 0004-0428, eISSN: 1988-8511, doi: 10.3989/aearte.2015.05 


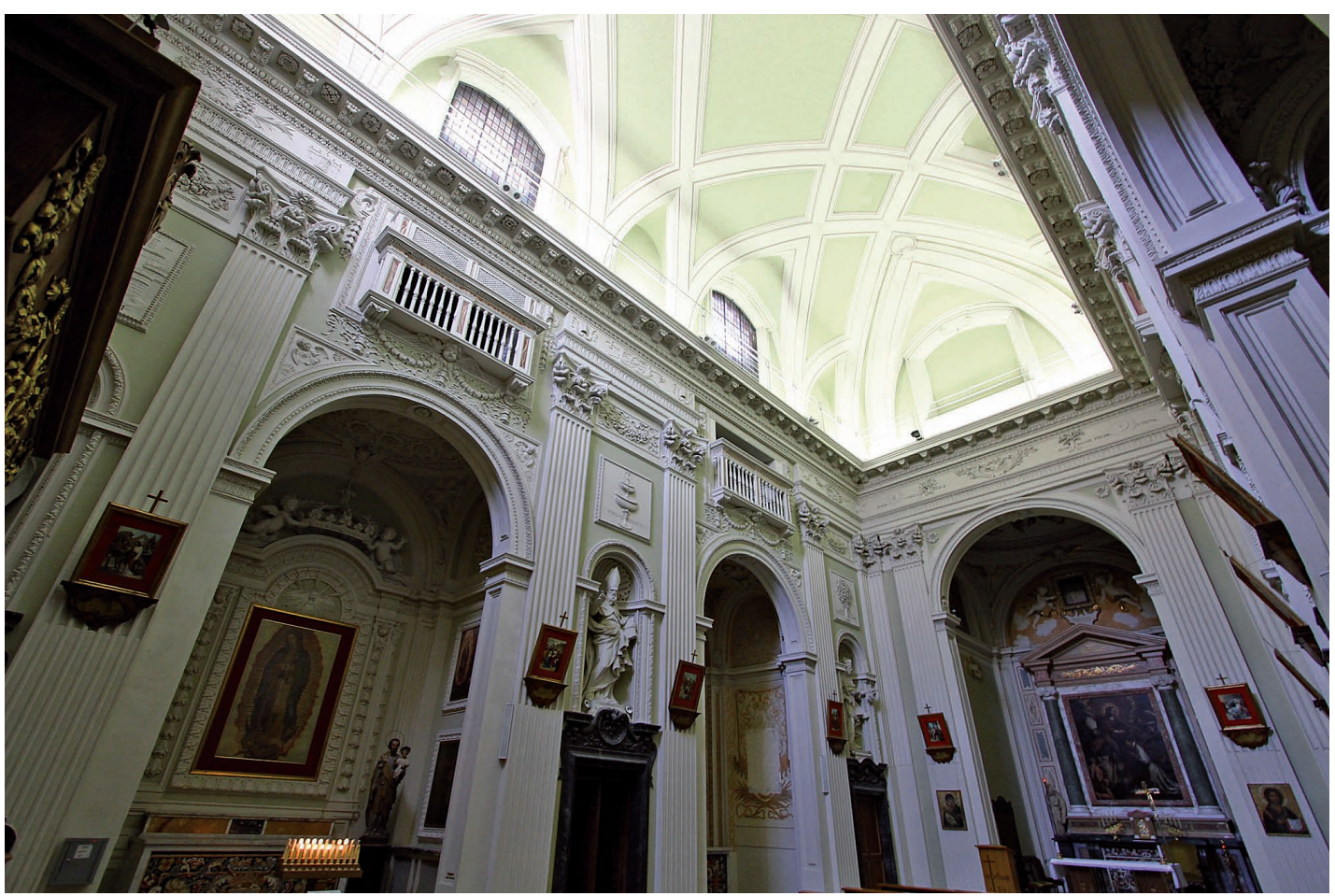

Fig. 1. Giuseppe Paglia. Iglesia del Hospicio de los santos Ildefonso y Tomás de Villanueva de la orden de agustinos recoletos. Roma. A partir de 1667.

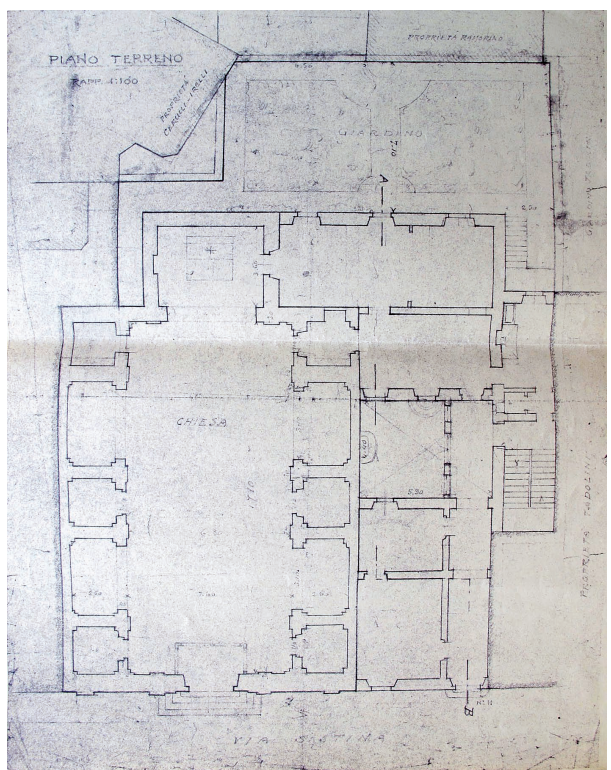

Fig. 2. Giacomo Malgherini. Planta del Hospicio de los santos Ildefonso y Tomás de Villanueva. 1902. AGOAR, Hospicio de Sant'Ildefonso, Caja 15.

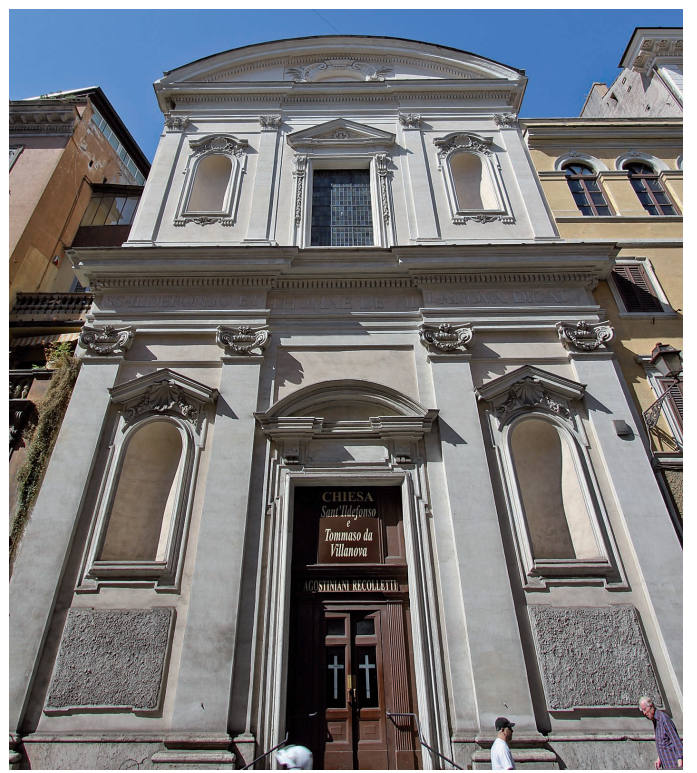

Fig. 3. Francesco Ferrari. Fachada del templo de los santos Ildefonso y Tomás de Villanueva. Roma. Primera mitad del S. XVIII.

Arch. esp. arte, LXXXVIII, 349, ENERO-MARZO 2015, 69-84

ISSN: 0004-0428, eISSN: 1988-8511, doi: 10.3989/aearte.2015.05 


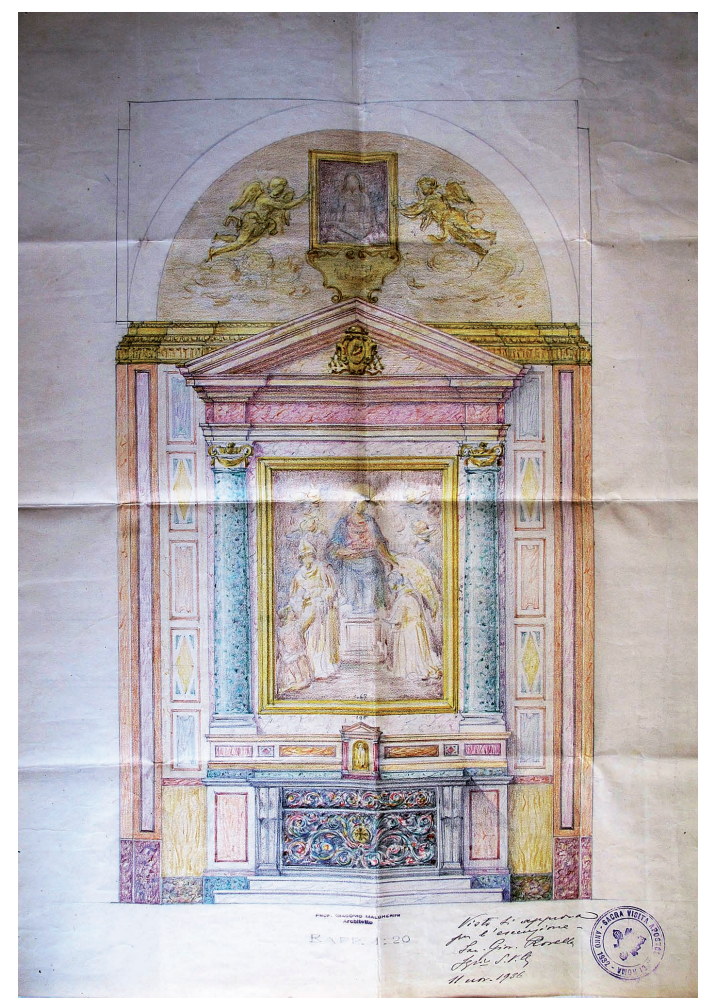

Fig. 4. Giacomo Malgherini. Proyecto para el altar mayor del templo de los santos Ildefonso y Tomás de Villanueva. 1936. AGOAR, Hospicio de Sant'Ildefonso, Caja 20, legajo 5. una pintura de ambos santos con la Virgen. La iglesia sería dotada de una fachada ordenada solo en los años veinte del siglo XVIII según proyecto de Francesco Ferrari, quien diseñó un imafronte tripartito de poco volumen con dos órdenes de pilastras ${ }^{4}$ (fig. 2).

En el Archivo General de la Orden en Roma se conserva una serie de documentos bastante completa que informa de las sucesivas intervenciones en la sede de la Via Sistina a partir del siglo XIX. La pérdida de toda documentación previa a la ocupación napoleónica hace imposible conocer las modificaciones que sobre el edificio pudieran haber sido realizadas durante el siglo XVIII, pero las crónicas y apuntes manuscritos, también conservados en el archivo de la orden, inducen a pensar que la configuración del conjunto, en lo estructural y decorativo, se mantendría en lo fundamental inalterada tal y como fue concebida en el Seiscientos (fig. 3).

Los levantamientos de planos de $1825 \mathrm{y}$ 1882 muestran reducción del solar del complejo habitacional de los agustinos ${ }^{5}$. Tras sucesivas restauraciones en $1852^{6}$, en los años sesenta y setenta ${ }^{7}$, así como una notable actualización del interior de la iglesia en $1888^{8}$, a principios del siglo XX se acometen en Hospicio profundas reformas para adaptar el edificio a su nueva condición de Curia General. Se construye ahora un altar mayor nuevo de mármol de Verano, quitando el cuadro de la Virgen de Copacabana y poniendo el que había en la capilla de San Ildefonso y Santo Tomás en su lugar ${ }^{9}$. La última intervención de calado sería la dotación de un nuevo altar para albergar el cuadro de los titulares en la capilla mayor que sería diseñado por Giacomo Malgherini en $1936^{10}$. La sólida estructura clasicista de columnas jónicas sancionaba definitivamente la marginación de la imagen de Copacabana que no encontraría lugar en el templo y sería almacenada lejos de la sede de Via Sistina (fig. 4).

\footnotetext{
${ }^{4}$ Vichi, 1961: 8-11. Una biografía profesional actualizada en Bevilacqua, 1991: 364. Véase Tancioni, 1989: 33-48.

5 AGOAR, Hospicio de Sant'Ildefonso, Caja 17 y Caja 14, Legajo 1.

${ }^{6}$ AGOAR, Hospicio de Sant'Ildefonso, Caja 14, Legajo 1.

7 AGOAR, Hospicio de Sant'Ildefonso, Caja 15.

${ }^{8}$ AGOAR, Hospicio de Sant'Ildefonso, Caja 14, Legajo 2.

9 AGOAR, Hospicio de Sant'Ildefonso, Caja 14.

10 AGOAR, Hospicio de Sant'Ildefonso, Caja 20, legajo 5.
}

Arch. esp. arte, LXXXVIII, 349, ENERO-MARZO 2015, 69-84 ISSN: 0004-0428, eISSN: 1988-8511, doi: 10.3989/aearte.2015.05 


\section{Las imágenes de Guadalupe y Copacabana, una vocación americanista}

Del conjunto del Hospicio de la Via Sistina el elemento de mayor relevancia, y el que ha llegado en mejores condiciones a la actualidad, es la iglesia. Esta toma la forma de aula rectangular de pequeñas dimensiones ordenada mediante pilastras corintias. Presenta dos capillas por flanco con tribunas sobre el trasdós de sus arcos y una, de dimensiones similares a las laterales, en la cabecera para albergar el altar mayor. En los paños entre los vanos de las capillas se disponen parejas de lesenas entre las cuales se abren hornacinas para albergar las esculturas de Santa Rita, San Fulgencio, San Fernando, Santa Clara de Montefalco, San Alipio y San Luís. La mayor particularidad del templo es, sin duda, su abovedamiento. Por encima del entablamento corrido que circunda todo el perímetro del aula se voltea una bóveda de cañón muy rebajado con lunetos triangulares para albergar las ventanas. Toda la superficie del cerramiento aparece recorrida por molduras que, a modo de nervios, evocan la malla estructural de una bóveda de crucería gótica. De cada pilastra arranca un arco que se torsiona formidablemente para recorrer diagonalmente el cañón y apear en una lesena del lado opuesto. Así, se constituye una red de arcos entrelazados que, además de su indudable valor ornamental, retoma ciertas propuestas de carácter barroco-gótico de enorme calado historiográfico que tienen su antecedente inmediato en la magnífica capilla de los Reyes Magos de Francesco Borromini en el cercano colegio de Propaganda Fide (fig. 5).

¿De qué manera pudo convertirse la modesta fundación agustina en la primera y más directa consecuencia de las propuestas de Borromini, por otro lado con un eco muy moderado en la arquitectura romana posterior? La respuesta debe buscarse en el poco conocido autor del proyecto, el arquitecto dominico siciliano Giuseppe Paglia ${ }^{11}$. Nacido en Palermo en 1616 aparece por primera vez en Roma, en el convento de Santa Maria sopra Minerva, en 1648. Sus primeras obras en la capital papal se centran en intervenciones en la sede dominica pero pronto se convierte en arquitecto del cardenal Virginio Orsini además de intervenir en la configuración arquitectónica de

\footnotetext{
${ }^{11}$ Forte, 1963: 281-409.
}

Arch. esp. arte, LXXXVIII, 349, ENERO-MARZO 2015, 69-84

ISSN: 0004-0428, eISSN: 1988-8511, doi: 10.3989/aearte.2015.05 
la plaza del Panteón o en los estudios sobre los problemas estructurales de la cúpula de San Pedro. Entre 1658 y 1667 trabaja en la construcción del colegio urbano de Propaganda Fide cubriendo diferentes cargos en la construcción proyectada por Borromini y es aquí, sin duda, donde conoce de primera mano la obra del lombardo que parafraseará en la sede de los agustinos recoletos. De hecho, Paglia sustituirá al propio Borromini al frente de la obra tras la muerte del maestro en 1667.

Pero más que la configuración arquitectónica de la iglesia, es significativa de la particular coyuntura histórica en la que se consolida la fundación su particular definición iconográfica que, a pesar de los desmanes sufridos, es fácil reconstruir en su aspecto original.

El inventario de 1856 da cuenta de los bienes muebles del Hospicio que tras la recuperación de la devastación napoleónica han sido recuperados por la institución ${ }^{12}$. En la capilla mayor presiden el templo la imagen de Nuestra Señora de Copacabana y, sobre ella, una pequeña imagen del Ecce Homo. A los lados completan la decoración dos pinturas de San José y San Andrés. En las dos capillas del lado del Evangelio se ubican el cuadro de los titulares del templo y el de la Virgen de Guadalupe con cuatro cuadritos menores, mientras que en el flanco opuesto presiden las capillas la pintura de la Inmaculada entre los Santos Agustín y Mónica y el relieve de mármol de la Natividad. El único cuadro que se registra en la sacristía es uno de Santa Clara.

En un inventario fechado el 10 de agosto de 1887 se detallan en la casa del procurador general los siguientes cuadros: San Andrés apóstol, Agar en el desierto, San Luís Gonzaga, Nuestra Señora de Copacabana, Santa Rosa de Lima, San Romualdo, dos cuadros con el Agnus Dei y uno con la degollación de San Juan. En la sacristía pinturas de un San Miguel Arcángel, el Descendimiento y Santa Mónica. Y en la iglesia el altar mayor y cuatro altares, un vía crucis de 14 lienzos, un cuadro de San José, uno de San Francisco Javier, dos cuadros del Corazón de Jesús, así como esculturas en hornacinas de Santa Rita de Casia, Santa Clara de Montefalco, Santo Tomás de Villanueva y San Ildefonso ${ }^{13}$.

Las seis esculturas de las hornacinas, aunque en el inventario de 1887 solo se citan cuatro de ellas, son de fecha incierta pero cercanas a las realizadas en los años setenta del siglo XVIII por Juan Adán para la iglesia española de Santa María de Monserrat ${ }^{14}$. Se trata de iconografías tradicionales de santos vinculados a la orden excepto las de los dos santos reyes, francés y español, que anteceden al altar mayor y que sugieren el acercamiento entre las dos casas reinantes a partir la instauración de un Borbón sobre el trono de España. Tampoco presenta mayor relevancia el contenido icónico de la mayor parte de las capillas: los dos cuadros, según algunos autores obra de Juan Correa, con la Virgen entre San Agustín y Santa Mónica y esta misma entre San Ildefonso y Santo Tomás de Villanueva, así como el relieve de la Natividad de Francesco Grassia en la capilla de San José.

Son, sin embargo, las imágenes marianas del templo las que dotan al conjunto de un carácter particular dentro del medio romano y que, engarzadas, dan a la fundación un sentido que entronca con la política hispana de la segunda mitad del siglo XVII. Dos imágenes de la Madre de Dios ocuparon originalmente el altar mayor y el de una de las capillas laterales del templo, respectivamente, la Virgen de Copacabana y la de Guadalupe.

Cronológicamente, la primera noticia que afecta a la configuración iconográfica del templo parece corresponder al cambio de su advocación, que suprime el nombre de Guillermo y lo sustituye por el del agustino Tomás de Villanueva. La canonización del que había sido arzobispo de Valencia tiene lugar en 1658 dentro de una política de la monarquía española que vería llevar a los altares durante el siglo XVII nada menos que a quince santos hispanos ${ }^{15}$. El ascenso meteórico

${ }^{12}$ AGOAR, Hospicio de Sant'Ildefonso, Caja 21, legajo 2.

13 AGOAR, Hospicio de Sant'Ildefonso, Caja 14.

${ }^{14}$ Véase De la Cruz Alcañiz, y García Sanchez, 2009: pp. 91-102.

${ }^{15}$ Gotor, 2007: 621-639. En realidad el número podría ascender a veinte si se considera la totalidad de los territorios del imperio español.

Arch. esp. arte, LXXXVIII, 349, ENERO-MARZO 2015, 69-84 ISSN: 0004-0428, eISSN: 1988-8511, doi: 10.3989/aearte.2015.05 
de las canonizaciones hispanas se vincula directamente a la imagen de los reyes Habsburgo como cabezas de una pretendida monarquía católica universal que se materializa en la pietas hispanica que la justifica y legitima ${ }^{16}$. El resultado inmediato en el medio romano sería la fundación de un templo, el de los agustinos recoletos, dedicado al nuevo héroe de la España católica. Sin embargo, los titulares del templo quedarían relegados durante siglos a uno de los altares laterales, siendo la Virgen de Copacabana la que presidiera el altar mayor asistida, a los pies de la iglesia, por otra advocación mariana, la de Guadalupe (fig. 6).

La Aurora de Copacabana que presidía el altar mayor de la iglesia de la Recolección en Roma, pintada según las fuentes por un desconocido Placido Siculo, corresponde a la imagen sobre tabla de esta Virgen de la Candelaria que se conserva hoy en la Curia General de los Agustinos Recoletos en Roma. Se trata de una vera efigies de la imagen escultórica americana que retrata, en dos dimensiones y con perfil recortado en su contorno, una imagen de vestir de perfil cónico de la Virgen con el Niño. Además de esta representación, en la misma sede, se conserva un lienzo de gran formato, también de época barroca, con la imagen

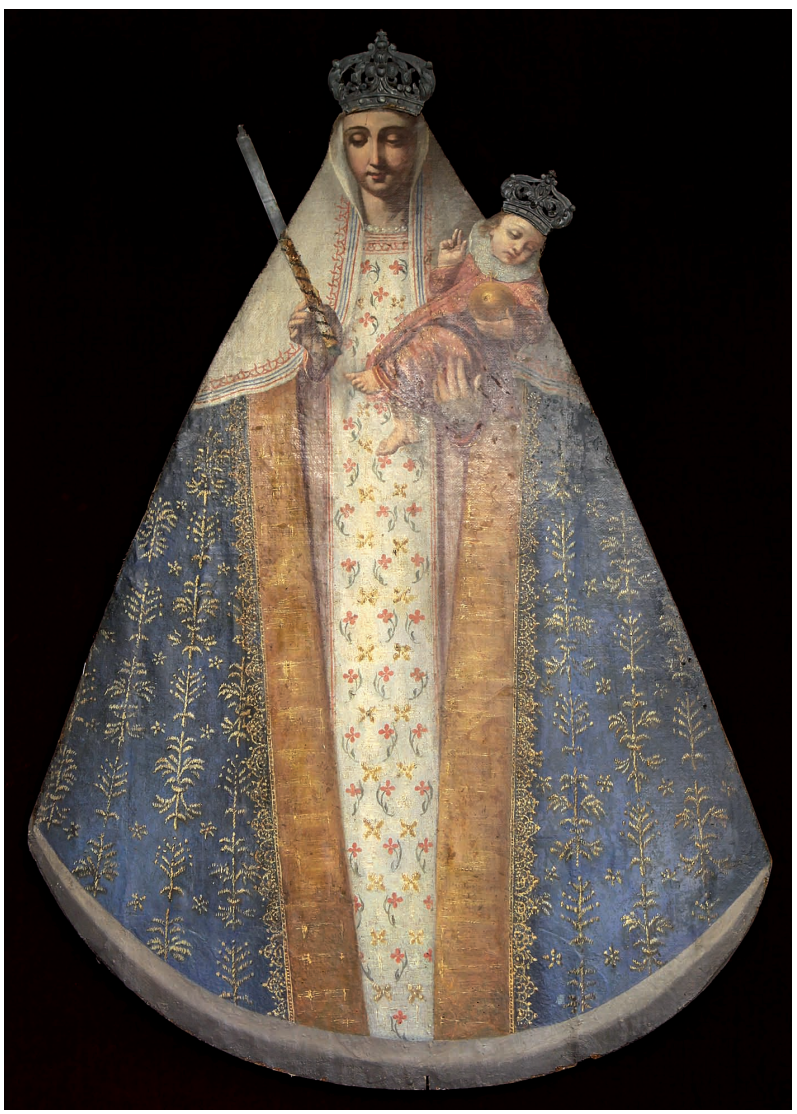

Fig. 6. Placido Siculo. Virgen de Copacabana que presidió, hasta el siglo XX, el altar mayor del templo de los santos Ildefonso y Tomás de Villanueva en Roma. 1655 circa. Foto de Pablo González Tornel. de la Virgen suspendida sobre un amplio paisaje que muestra el santuario de Copacabana en el lago Titicaca y que se corresponde, probablemente, con la obra de esta temática censada en el inventario de 1887 y ubicada en casa del procurador general. La primera representación, más primitiva, se corresponde con la imagen entregada en Roma por el Padre Aguirre, y su perfil recortado parece indicar un primitivo empleo como estandarte procesional.

La devoción a la Virgen de Copacabana, a partir del santuario peruano regido por la orden agustina en el lago Titicaca, se inserta, tardíamente, en la irradiación de las devociones novohis-

${ }^{16}$ Esta pietas hispanica se materializa como una de las versiones de la general pietas austriaca que caracteriza a las dos ramas de la dinastía, la española y la imperial, y que vincula la familia Habsburgo y su gloria directamente con un carácter profundamente católico, practicante y militante, que llevará al linaje a convertirse en defensores acérrimos de determinadas advocaciones, de sacramentos como la eucaristía, o de misterios como el de la Inmaculada Concepción de la Virgen. Véase al respecto Coreth, 2004.

Arch. esp. arte, LXXXVIII, 349, ENERO-MARZO 2015, 69-84

ISSN: 0004-0428, eISSN: 1988-8511, doi: 10.3989/aearte.2015.05 


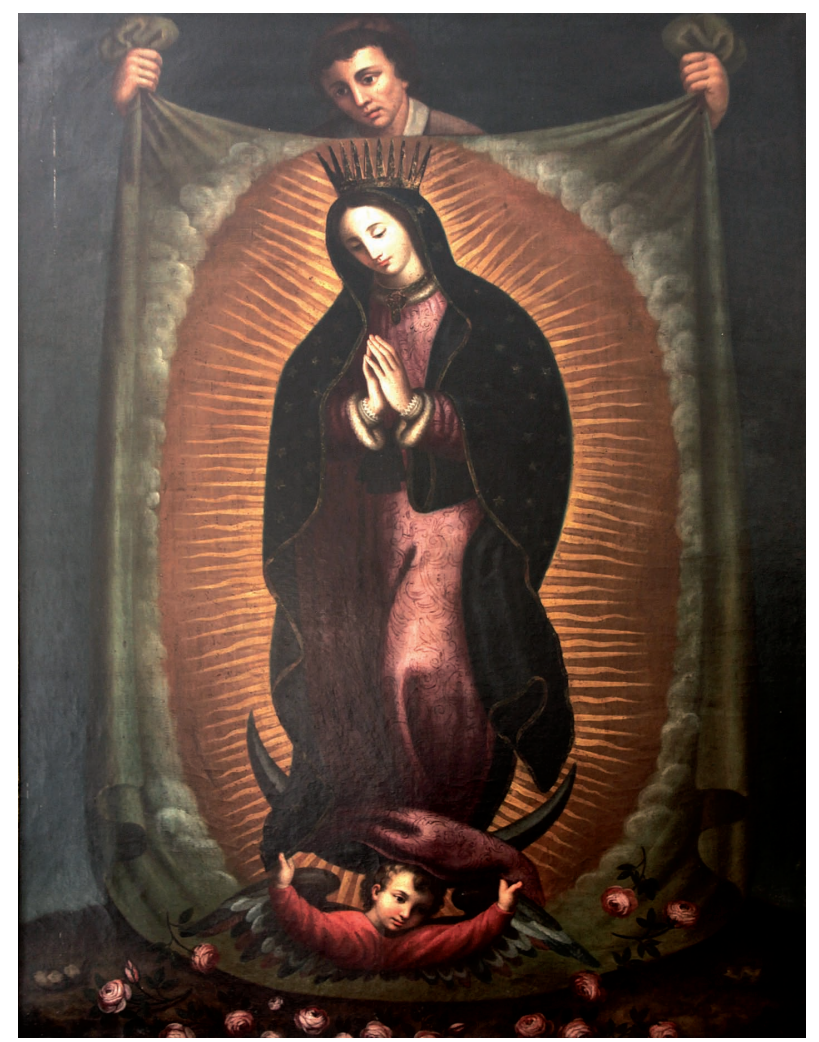

Fig. 7. Juan Correa. Virgen de Guadalupe. Primera capilla del lado del Evangelio en el templo de los santos Ildefonso y Tomás de Villanueva en Roma. S. XVII.

panas en el Viejo Mundo, con la Virgen de Guadalupe a la cabeza ${ }^{17}$. La llegada a Europa se vincula con la acción del agustino peruano Miguel de Aguirre a partir de 1650, y así, entre 1652 y 1665 se entronizan en España al menos seis imágenes de la Virgen de Copacabana, se crean dos cofradías dedicadas a la misma y se publican dos tratados explicando su carácter milagroso ${ }^{18}$.

Por lo que respecta a la imagen de la Virgen de Guadalupe, atribuida al mexicano Juan Correa y fechable en la segunda mitad del siglo XVII, aparece en el Hospicio romano con una elaborada composición formada por la imagen mariana central y cuatro pequeños cuadros con las apariciones guadalupanas a Juan Diego. Los originales se conservan en la Curia General, habiéndose perdido una de las historias secundarias. El lienzo central de la Virgen de Guadalupe muestra a un personaje masculino aparentemente con hábito monástico sustentando el tepeyac con la milagrosa imagen mariana, elemento que, junto a los estucos de tema mariano de la capilla, inducen a pensar en la ideación de un espacio con esta dedicación desde el primer momento de la construcción de la iglesia.

La devoción mexicana a la virgen de Guadalupe es anterior a la consolidación del culto de Copacabana y desarrolla, ya en el siglo XVI, una iconografía y tipos muy concretos y, como en el caso de la patrona del Perú, su éxito se asociara tempranamente al carácter milagrero de la imagen ${ }^{19}$. Se trata en este caso de una Virgen de tipo apocalíptico que se vincula con el auge de la devoción a la Inmaculada Concepción en el mundo hispánico ${ }^{20}$, y que adquiriría una notable y temprana difusión en Europa ${ }^{21}$. Juan Correa, el autor de de la efigie romana, será, con Miguel Cabrera en el siglo XVIII, uno de los pintores que contribuirán de manera decisiva a la fijación y difusión de la iconografía de la patrona de México, adscribiéndosele algunos de los ejemplos conservados en España ${ }^{22}$ (fig. 7).

\footnotetext{
17 Véanse Ramos Gavilán, 1976. Salles-Reese, 2008.

${ }^{18}$ Rípodas Ardanaz, 1995: 47-78. El más completo de los libros publicados en la corte española en estos primeros momentos es León, 1663.

19 San José, 1743.

${ }^{20}$ Cuadriello, 2001. Vargas Lugo, 1987: 57-61.

${ }^{21}$ Cuadriello, 1991: 268-288. Véase, para el caso español, Barea Azcón, 2007: 177-206.

22 Sebastián, S1976: 65-66.
}

Arch. esp. arte, LXXXVIII, 349, ENERO-MARZO 2015, 69-84 ISSN: 0004-0428, eISSN: 1988-8511, doi: 10.3989/aearte.2015.05 
La presencia de las iconografías marianas de Guadalupe y Copacabana en el medio romano de la segunda mitad del siglo XVII se vincula con la vocación misionera y americana de la Orden de los Agustinos, pero tiene implicaciones más profundas. La patrona de México era ya venerada en Roma antes de su inclusión en el conjunto hagiográfico recoleto, y parece que la imagen más antigua en la ciudad es la del templo de San Nicola in Carcere ${ }^{23}$. Pero la imagen de Copacabana llegada al Hospicio en 1655 es la primara aparición de la patrona del Perú en suelo italiano y de manera inmediata a la donación de la imagen se publicaría en Roma una relación de sus milagros en una suerte de campaña publicitaria para potenciar el culto a esta nueva advocación de origen netamente hispano ${ }^{24}$.

El cambio de orientación y la potenciación mariana y americana del templo, además de coyuntural, parece encontrarse en la presencia del culto agustino americano Miguel de Aguirre en Roma en 1655. El padre Aguirre, nacido en La Plata hacia 1598 y catedrático en las Universidades de San Marcos y Lima, llega a España con el Virrey del Perú, don Pedro de Toledo y Leyva, marqués de Mancera, en 1650. En Madrid reside en las sedes agustinas de doña María de Aragón, San Felipe el Real y los Agustinos Recoletos, e introduce en la capital la devoción a la Virgen de Copacabana ${ }^{25}$. En el Colegio de Doña María de Aragón o de la Encarnación, Miguel de Aguirre es responsable de buena parte de la dispersa o desaparecida decoración pictórica que ornaba el templo. Mandó colocar dos cuadros de tema mariano en el presbiterio, una Inmaculada Concepción y una Virgen rodeada de doctores, santos, pontífice, cardenales y obispos, varias pinturas en la capilla del Cristo de la Buena Muerte, en la de Santa Catalina y en la nave. En el templo de San Agustín, llamado de Copacabana o de Recoletos, sede madrileña de la Recolección, Aguirre fundó una capilla dedicada a la Virgen de Copacabana, al parecer la de mayor magnificencia de la iglesia, presidida por una imagen que él mismo había traído del Perú ${ }^{26}$.

\section{La definición inmaculista de la sede romana de la Recolección}

La fuerte impronta mariana de la idea original del Hospicio de los santos Ildefonso y Tomás de Villanueva se ve reforzada cuando uno se aproxima a la decoración estucada que reviste el templo. El friso que recorre el perímetro de la iglesia muestra, sobre la puerta de entrada, su verdadera advocación dentro de un medallón en el que se lee "S. Maria de Copacavana ora pro nobis". Si bien en parte del entablamento encontramos esculpidos los corazones de los agustinos y los báculos de los titulares, en el resto se representan símbolos marianos. A los pies la torre, la puerta del cielo, las flores con el texto "flos campi", el espejo con el escrito "speculum sine macula", el ciprés con el lema "quasi cipresis", la puerta del edén con el texto "ostium paradisi", una escalera con el lema "scala dei", una estrella y la imagen de un templo. Y en la cabecera un sol con el texto "electa ut sol", un árbol acompañado de "quasi cedrus", una palmera con el escrito "quasi palma" y una luna llena con el lema "pulchra ut luna". Además, por encima de los arcos que cierran las seis hornacinas de los muros de la nave, se recortan placas que ostentan relieves de estucos igualmente dedicados a la Virgen. Las imágenes reflejadas son un árbol florido con el texto "quasi plantatio rosae in iericho", un pozo con el lema "puteus aquar viventium", un dragón de siete cabezas acompañado del escrito "ipsa con teret", una ciudad amurallada con el lema "civitas dei", una fuente acompañada por "fons signatius" y un árbol con el texto "quasi oliva speciosa in campis" (fig. 8).

\footnotetext{
${ }^{23}$ Pulcini, 1957.

${ }^{24}$ Marraci, 1656.

${ }^{25}$ Santiago Vela, 1913: 60-63.

${ }^{26}$ Iturbe, 2007: 335-368. Sobre el convento de Recoletos de Madrid y la capilla de Copacabana véase Díaz Moreno, y Lopezosa Aparicio, 1989: 181-206.
}

Arch. esp. arte, LXXXVIII, 349, ENERO-MARZO 2015, 69-84

ISSN: 0004-0428, eISSN: 1988-8511, doi: 10.3989/aearte.2015.05 

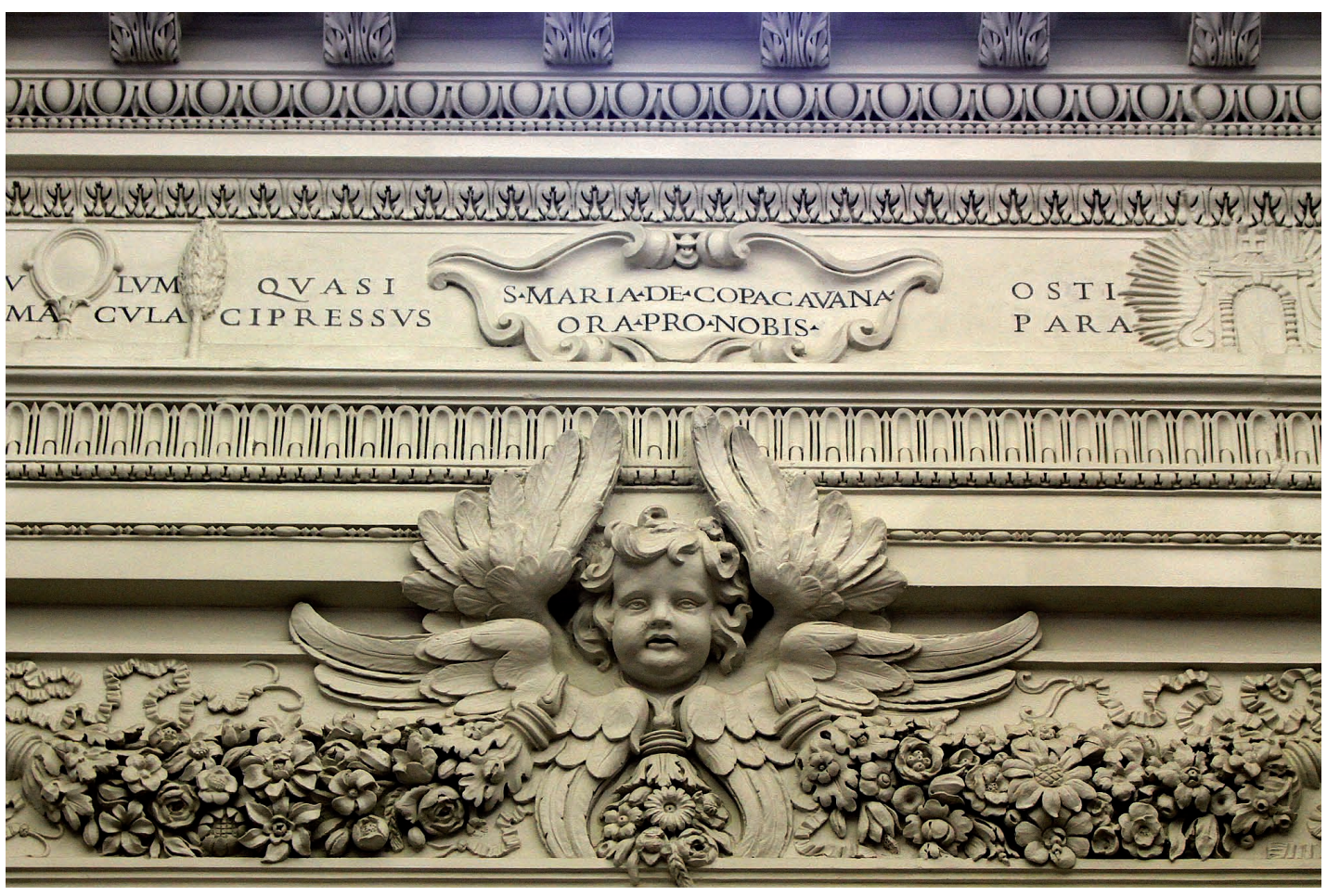

Fig. 8. Antonio y Carlo Cometti. Detalle de los estucos del templo de los santos Ildefonso y Tomás de Villanueva con la dedicación del mismo a la Virgen de Copacabana. Roma. A partir de 1667.

El complejo aparato simbólico de los estucos del templo de los agustinos recoletos en Roma proviene de de una tradición icónica que, nacida en el siglo XV, se concretaría en los versos de la Letanía Lauretana poco después, a través de una serie de figuras extraídas del Antiguo Testamento que ensalzan la figura de la Virgen y su Concepción Inmaculada ${ }^{27}$. El carácter concepcionista del templo agustino construido en la Via Sistina no resulta extraño si se lo relaciona con la situación política que lo rodeó. Así como las canonizaciones se habían convertido en el siglo XVII en una verdadera muestra de poder ante la mayor autoridad espiritual del orbe y en una legitimación de la autoridad de la monarquía española, lo propio ocurre con la devoción a la Virgen y, en particular, con el misterio de su Concepción Inmaculada. Aunque no se convertiría en dogma hasta 1854, la celebración de fiestas en su honor por parte de la comunidad hispana así como la plasmación icónica de la devoción eran frecuentes.

Como ha sido analizado de manera ejemplar por Suzanne Stratton, la devoción al misterio de la Inmaculada Concepción de la Virgen María se identifica con la monarquía española solo en plena Edad Moderna y, en concreto, ya en el siglo XVII ${ }^{28}$. A pesar de su creciente popularidad desde finales de la Baja Edad Media, ni Carlos V ni Felipe II mostrarían demasiado interés por la definición del dogma y durante el siglo XVI el debate entre maculistas e inmaculistas se mantendría alejado de la corona y centrado en la contraposición de los puntos de vista defendidos, a veces

\footnotetext{
${ }^{27}$ Sebastían, 1981: 207-215.

${ }_{28}$ Stratton, 1994.
}

Arch. esp. arte, LXXXVIII, 349, ENERO-MARZO 2015, 69-84 ISSN: 0004-0428, eISSN: 1988-8511, doi: 10.3989/aearte.2015.05 
de manera virulenta, por franciscanos y dominicos. La indefinición papal frente a las demandas de un sector de la iglesia produciría que, en los albores de la Edad Moderna, la representación icónica del misterio quedara limitada, en la mayoría de las ocasiones, a su imbricación con tipos iconográfico como el árbol de Jessé o el abrazo ante la puerta dorada. Es, sin embargo, durante el quinientos cuando, fruto de la intensa defensa de las tesis inmaculistas por parte de franciscanos, carmelitas y jesuitas, se fijará una iconografía propia para el deseado dogma de la Inmaculada Concepción, la llamada Virgen Tota Pulchra.

La imagen Tota Pulchra de María, con algunos elementos variables, implica la presencia de la Virgen aislada y rodeada de una serie de símbolos de su pureza inmaculada muchas veces acompañados de cartelas explicativas. Así aparece tipificada en el tratado sobre las imágenes sagradas de Molanus en 1570, aunque la tradición contaba ya entonces con casi un siglo de existencia ${ }^{29}$. Stratton retrotrae la fecha de la inicial aparición

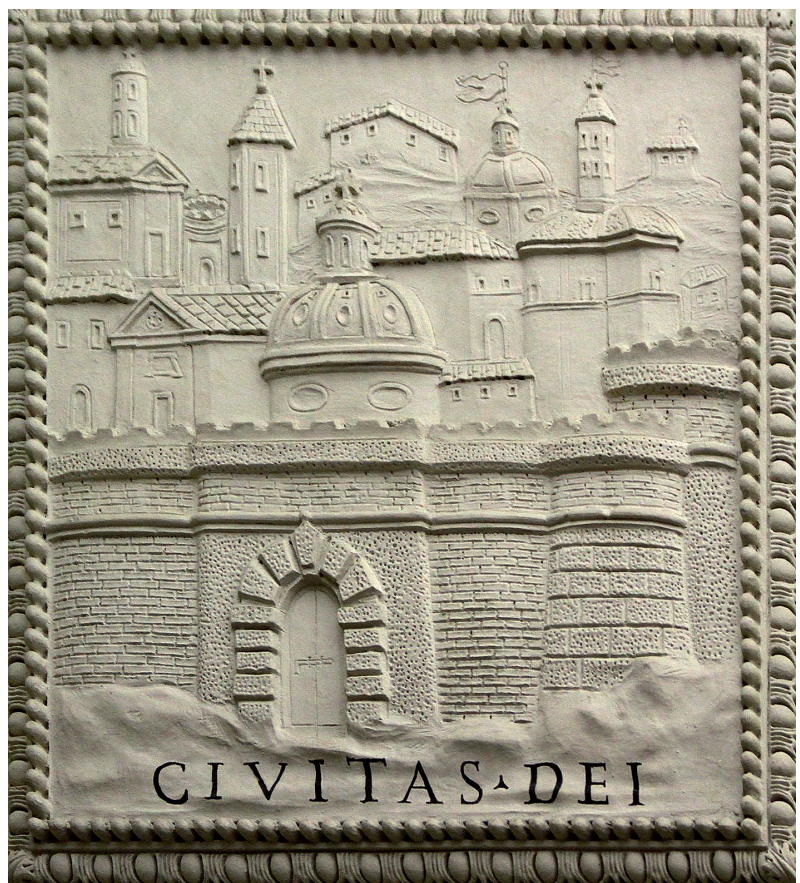

Fig. 9. Antonio y Carlo Cometti. Fragmento de los estucos del templo de los santos Ildefonso y Tomás de Villanueva con una de los emblemas inmaculistas que caracterizan la imagen de la Virgen Tota Pulchra. Roma. A partir de 1667. de la imagen de la Tota Pulchra en el mundo del grabado a 1503, y su primera plasmación artística, en el medio francés, a 1484. Los símbolos que rodean a la Virgen tienen, por su parte, un origen literario. La mayoría de ellos, Sol, Stella, Luna, Porta Coeli, Lilium inter spinas, Speculum sine macula, Hortus conclusus, Fons signatius y Civitas Dei, según Molanus, provienen del Cantar de los Cantares, aunque su número no es el mismo en todas las representaciones artísticas, y a los citadas por Molanus se añadirán con frecuencia otros como la Virga Jessé, Oliva speciosa, Turris David, Scala caeli, Templum Dei o Quasi cypressun in Sion (fig. 9).

Aunque su aparición en las artes es anterior, la fijación literaria de la simbología mariana que rodea a la Inmaculada procede de la letanía lauretana, compuesta hacia 1500. Una procedencia distinta tiene la configuración de la propia figura de la Virgen como mujer apocalíptica caracterizada por la luna creciente bajo sus pies, los rayos de sol que salen de ella y la corona de doce estrellas $^{30}$. Esta mulier amicta sole no es privativa de las representaciones inmaculistas, aunque sería en estas donde alcanzaría mayor desarrollo, y así, en fechas anteriores a la fijación del tipo de la Tota Pulchra, se asocia con frecuencia a la representación de la Virgen del Rosario, frecuente en el arte vinculado a los dominicos ${ }^{31}$. Esta representación de la Madre de Dios en la visión apocalíptica de San Juan resulta interesante porque incluye la presencia del Niño dentro de la iconografía de la mulier amicta sole, algo poco frecuente en las posteriores plasmaciones inmaculistas.

\footnotetext{
${ }^{29}$ Molanus, 1570.

${ }^{30}$ Vetter, 1958-59: 32-71.

${ }^{31}$ Ringbom, 1962: 326-330.
}

Arch. esp. arte, LXXXVIII, 349, ENERO-MARZO 2015, 69-84

ISSN: 0004-0428, eISSN: 1988-8511, doi: 10.3989/aearte.2015.05 
La fusión de la mujer apocalíptica con los atributos emblemáticos descritos por Molanus se fijaría como iconografía de la Inmaculada Concepción solo a partir del Concilio de Trento, y la tipología se difundiría con rapidez gracias a los grabadores flamencos como Martin de Vos o los hermanos Wierix, y a la actividad de jesuitas como Jerónimo Nada ${ }^{32}$. Desde este momento, tras fijarse una iconografía completa postridentina y contrarreformista para una devoción no del todo reconocida por el Papa, la identificación de la misma con la corona española y los reyes de la dinastía Habsburgo experimentaría una carrera ascendente.

Durante los primeros años del siglo XVII continuarían las controversias inmaculistas, protagonizadas fundamentalmente por dominicos y franciscanos, particularmente en la ciudad de Sevilla. Sin embargo, el espaldarazo definitivo a las doctrinas a favor de la Inmaculada Concepción llegaría en 1616 con la creación por parte de Felipe III de una Real Junta destinada a defender la definición del dogma ante el Papado ${ }^{33}$. A este momento de exaltación inmaculista corresponde la magnífica y compleja composición de Juan de Roelas que se conserva en el Museo Nacional de Escultura. El decidido apoyo del monarca, que crearía una segunda junta en 1617 y aún una tercera en 1618, no logró ningún avance significativo en la definición del dogma, pero consiguió, por un lado, popularizar la controversia hasta el punto que Lope de Vega le dedicó una pieza teatral ${ }^{34}$, y por otro, identificar a los reyes de España con esta devoción y plantear la consecución de su definición como dogma como una batalla de la monarquía española cuyo éxito significaría una gran victoria.

Felipe IV se convertiría en el gran campeón de la defensa del dogma y así lo demuestra la abundante iconografía en la que el rey y la Virgen aparecen unidos. Desde el lienzo de Pedro Valpuesta con Felipe IV jura defender la Inmaculada Concepción de María (Madrid, Museo Municipal), al grabado de 1631 sobre dibujo de Rubens que lo muestra con Don Carlos, el Cardenal Infante Fernando y el príncipe Baltasar Carlos, o la pintura de Pietro del Po, de hacia 1662, en la que aparece junto a Mariana de Austria, el futuro Carlos II y el Cardenal Pascual de Aragón adorando a María (Toledo, Catedral) ${ }^{35}$.

Las misiones inmaculistas durante el reinado de Felipe IV se suceden y se consolida la idea de la necesidad de la definición del dogma al vincular la gloria de la monarquía española con la protección de la Virgen. Algunas de las embajadas realizadas en este sentido dejaron huella en las producciones artísticas conservadas en Roma, como el lienzo de Louis Cousin pintado para presidir la capilla de la Inmaculada en el templo nacional de Santiago y hoy en Monserrat que conmemora la pírrica victoria obtenida por el emisario Bernardo del Toro en $1630^{36}$. No sería, sin embargo, hasta 1661, con la bula Sollicitudo Omium Eclessiarum, cuando Luís Crespí de Valldaura obtendría de Alejandro VII un verdadero éxito en el camino hacia la definición del dogma ${ }^{37}$. Durante el reinado de Carlos II la Inmaculada Concepción se mantendría como protectora de la monarquía y estandarte principal de la pietas austriaca en su variante de pietas hispanica ${ }^{38}$.

\footnotetext{
32 Buser, 1976: 424-433.

${ }^{33}$ Pou y Martí, 1931: 371-417, 508-534; 1932: 72-88, 424-434; 1933: 5-48.

${ }^{34}$ La pieza teatral, titulada La limpieza no Manchada, se encuentra dentro del volumen Relación de las fiestas que la Universidad de Salamanca celebró desde 27 hasta 31 de octubre del año de 1618, al juramento del nuevo estatuto, hecho en 2 de mayo del dicho año, de que todos los graduados defenderán la pura y limpia Concepción de la Virgen Nuestra Señora, concebida sin mancha de pecado original. Ordenada por mandado y comisión de la misma Universidad en su claustro pleno. Con licencia del ordinario, 1618.

35 Algunas de estas imágenes, además de la presentación del monarca como principal abanderado de la causa de la Inmaculada, poseen una condensación de significados mucho mayor, tal y como ha demostrado Carrió Invernizzi, 2008: pp. $85-100$.

${ }^{36}$ Cacho, 2003: 415-426.

37 Gutiérrez, 1955: 7-480. Véase también Anselmi, (ed.), 2008.

${ }^{38}$ Son frecuentes los textos panegíricos como el de Santa María, 1682.
}

Arch. esp. arte, LXXXVIII, 349, ENERO-MARZO 2015, 69-84 ISSN: 0004-0428, eISSN: 1988-8511, doi: 10.3989/aearte.2015.05 


\section{La sede romana de los agustinos recoletos, compendio de devociones hispanas}

En 1667 se ponía la primera piedra del Hospicio de San Ildefonso y Santo Tomás de Villanueva en la Via Sistina romana. La fundación, que correspondía a una rama de los agustinos, la Recolección, parecía, en sus orígenes, destinada a convertirse en una modesta casa dedicada a San Guillermo y San Ildefonso. Sin embargo, a partir de la intervención del peruano Miguel de Aguirre, que donaba una imagen de la Virgen de Copacabana, se aceleraban los cambios que modificarían la iconografía y el simbolismo del nuevo templo. La iglesia pasaba a dedicarse, junto al patrón toledano San Ildefonso, a Santo Tomás de Villanueva, uno de los nuevos héroes del catolicismo hispano canonizado en 1658. Sin embargo, lo que pasaría a caracterizar de manera inequívoca la nueva iglesia serían las devociones americanas a Copacabana y Guadalupe y su configuración como espacio simbólico inmaculista que definirían un verdadero monumento al catolicismo defendido por la monarquía española.

La reunión de cuatro devociones vinculadas fuertemente a la los reyes de España entronca perfectamente con la situación romana del siglo XVII. Como ha analizado José Luís Colomer, durante la centuria las celebraciones religiosas romanas, y también las laicas, fueron vistas por las distintas naciones como una ocasión para desplegar el propio poderío en la capital papal ${ }^{39}$. En una ciudad fuertemente marcada por los ritos, rituales y fiestas, un evento como una canonización, la celebración de la Pascua o una bula favorable a las pretensiones españolas, se erigía en una ocasión perfecta para llenar la urbe de escudos, retratos y otros adobos que cantaban, de manera efímera, las glorias del reinante. En algunos casos estas celebraciones efímeras tuvieron la fuerza suficiente para convertirse en obras de arte y arquitectura perdurables, y así, ya Tormo, en los años cuarenta del siglo XX, en su monumental obra acerca de la presencia española y portuguesa en el medio artístico romano, diferenció y contrapuso los templos principales sufragáneos de la iglesia nacional española de San Giacomo, que serían Monserrato, la Trinità de Via Condotti, Sant'Ildefonso en la Via Sistina, San Pasquale e Santi Quaranta, Santa Maria i San Giovanni in Campo Marzio y San Carlo alle tre Fontane; y las francesas sufragáneas de San Luigi, que corresponderían a la Trinità dei Monti, San Salvatore ad Thermas, Sant'Ivo, San Nicola, San Dionisio, San Claudio y Santa Maria della Purificazione ${ }^{40}$.

Pero por qué construir un monumento dedicado al catolicismo español, mariano e inmaculista, en las estribaciones de la colina del Pincio? Pocos años antes de la construcción del Hospicio agustino dedicado a la Virgen de Copacabana se había establecido, a pocos metros, la embajada estable de España en el Palacio Moladeschi ${ }^{41}$. El edificio, comprado por el conde de Oñate en 1647, pasaba en 1654 a la corona constituyéndose en la primera representación diplomática estable de un estado en Roma $^{42}$. La presencia española en la zona de expansión hacia el Quirinal se veía reforzada por la particular vinculación de la monarquía con la basílica de Santa María la Mayor, en cuyo atrio se ubicó, durante los años de la construcción del Hospicio agustino, una escultura de Felipe IV, y frente a la que se había erguido, en 1614, una columna coronada por la imagen de la Inmaculada Concepción ${ }^{43}$.

Como contrapunto a la presencia española en la zona se encuentra, al inicio de la Via Sistina, el convento de mínimos de la Trinidad, de patronato francés y, por lo tanto, representante del gran antagonista de la corona española en el siglo XVII. Muestra de la lucha diplomática entre Francia y España por el dominio del espacio urbano es el intento que en 1660 emprende, por orden del Cardenal

\footnotetext{
${ }^{39}$ Colomer, 2000: 346-357.

40 Tormo y Monzó, 1942, tomo I: 59. Véase para un acercamiento actualizado a la casuística de la presencia artística de los españoles en el medio romano de los siglos XVII y XVIII Anselmi, 2012.

41 Anselmi, 2001.

42 Anselmi, 2001: 70 .

${ }^{43}$ Fernández Alfonso, 1995: 799-810. Véanse, además, Carrió Invernizzi, 2007: 255-270, y Bodart, 2007: 679-694.
}

Arch. esp. arte, LXXXVIII, 349, ENERO-MARZO 2015, 69-84

ISSN: 0004-0428, eISSN: 1988-8511, doi: 10.3989/aearte.2015.05 
Mazzarino, Elpidio Benedetti, agente galo, de urbanizar la subida al Pincio ${ }^{44}$. El proyecto, con un fuerte carácter celebraticio de la monarquía francesa y organizado en torno a una estatua ecuestre de Luís XIV, habría supuesto un verdadero desafío diplomático ante la fachada de la embajada de España $^{45}$. Aunque la escalinata no sería, de momento, llevada a cabo, el barrio en disputa se convertiría durante décadas en espacio privilegiado de los enfrentamientos entre ambas naciones ${ }^{46}$.

Las iglesias nacionales así como las fundaciones religiosas contribuían a reforzar la presencia de una determinada nación ante el Papa y en el caso de la monarquía española, pretendidamente adalid del catolicismo, dicha presencia resultaba fundamental. Los intentos hispanos de afianzarse en la zona que une la plaza de España con el Quirinal son rastreables mucho antes de la ofensiva de Benedetti o de la construcción del Hospicio de los Agustinos Recoletos. En 1622 se crea en la inmediata vecindad del convento francés de mínimos la fundación franciscana de Sant'Isidoro ${ }^{47}$, consecuencia directa de la canonización del patrono de Madrid ese mismo año, hecho que, con la elevación a los altares de nada menos que cuatro santos españoles, se convertía en un auténtico triunfo para Felipe $\mathrm{IV}^{48}$. Sin embargo, ante la falta de fondos, la fundación pronto pasaría de la órbita española a la irlandesa, añadiendo la advocación de San Patricio a la original, y sería necesario buscar un nuevo contrapeso a la presencia francesa. Habría que esperar unas décadas, pero en 1667, pocos años después del desafío de los proyectos para la escalinata de Plaza de España, la puesta de la primera piedra de una iglesia que tomaba el nombre de otro héroe del catolicismo hispano, Santo Tomás de Villanueva, se convertía en un monumento a la devoción más querida por los reyes de España, la Concepción Inmaculada de la Virgen María. Se conseguía de esta manera otro efímero éxito de una diplomacia en la que política y religión aparecían indisolublemente entrelazadas.

\section{BIBLIOGRAFÍA}

Alloisi, S. (1996): "La scalinata tra storia e progetto". En VV. AA., La scalinata di Trinità dei Monti, Milán, Vallardi, pp. 43-94.

Anselmi, Alessandra (2001), Il Palazzo dell'Ambasciata di Spagna presso la Santa Sede, Roma, De Luca.

Anselmi, Alessandra (2003): "Roma celebra la monarchia spagnola: il teatro per la cannonizazione di Isidoro Agricola, Ignazio di Loyola, Francesco Saverio, Teresa de Gesù e Filippo Neri (1622)”. En Colomer, José Luís (dir.), Arte y diplomacia de la Monarquía Hispánica en el siglo XVIII, Madrid, Fernando Villaverde, pp. 221-246.

Anselmi, Alessandra (2008): (ed.), L'Immacolata nei rapporti tra l'Italia e la Spagna, Roma, De Luca Editori d'Arte.

Anselmi, Alessandra (2012): Le chiese spagnole nella Roma del Seicento e del Settecento, Roma, Gangemi. Barea Azcón, Patricia (2007): "La iconografía de la Virgen de Guadalupe de México en España". En Archivo Español de Arte, LXXX, 318, pp. 177-206.

Bevilacqua, Mario (1991): "Ferari, Matteo". En Contardi, B., y Curcio, G. (comisarios), In urbe architectus. Modelli, Disegni, Misure. La professione dell'architetto a Roma 1680-1750, Roma, Àrgos, p. 364.

Bodart, Diane H. (2007): "La guerre des estatues. Monuments des rois de France et d'Espagne à Rome au XVIIe siècle". En Hernando Sánchez, Carlos José (coord.), Roma y España. Un crisol de la cultura europea en la Edad Moderna, Madrid, Seacex, pp. 679-694.

${ }^{44}$ Véase para la reconstrucción del proceso proyectual de la escalinata Lotz, 1969: 39-94. Para una visión de los proyectos y la efectiva realización en el siglo XVIII VV. AA., 1996.

45 Véanse Laurain-Portemer, 1968: 273-294. Marder, 1980: 286-289. Alloisi, 1996: 43-94.

${ }^{46}$ Gigli, 1997: 202-211.

47 Daly, 1971.

48 Anselmi, 2003: 221-246.

Arch. esp. arte, LXXXVIII, 349, ENERO-MARZO 2015, 69-84 ISSN: 0004-0428, eISSN: 1988-8511, doi: 10.3989/aearte.2015.05 
Buser, Thomas (1976): “Jerome Nadal and Early Jesuit Art in Rome". En Arte Bulletin, 58, pp. 424-433.

Cacho, Marta (2003): "Una embajada concepcionista a Roma y un lienzo conmemorativo de Louis Cousin". En Colomer, José Luis (dir.), Arte y diplomacia de la Monarquía Hispánica en el siglo XVIII, Madrid, Fernando Villaverde, pp. 415-426.

Carrió Invernizzi, Diana (2007): "La estatua de Felipe IV en Santa Maria Maggiore y la embajada romana de Pedro Antonio de Aragón (1664-1666)”. En Roma moderna e contemporanea, 1-3, pp. 255-270.

Carrió Invernizzi, Diana (2008): "El poder de un testimonio visual: el retrato de Felipe IV y Pascual de Aragón, de Pietro del Po (1662)”. En Palos i Peñarroya, Joan Lluís, y Carrió Invernizzi, Diana, La historia imaginada: construcciones visuales del pasado en la Época Moderna, Madrid, Centro de Estudios de Europa Hispánica, pp. 85-100.

Chappell, M. (1983): “Bernini and Francesco Grassia's «Allegory of human life»: the origins and clarification of some erroneous suppositions”. En Southeastern College Art Conference Review, X, pp. 126-134.

Colomer, José Luís (2000): "Luoghi e attori della "pietas hispanica" a Roma all'epoca di Borromini”. En Francesco Borromini (actas del congreso), Milán, Electa, pp. 346-357.

Coreth, Anna (2004): Pietas austriaca, West Lafayette, Indiana, Purdue University Press.

Cuadriello, Jaime (com.) (2001): «El divino pintor: la celebración de María de Guadalupe en el taller celestial». México D.F., Museo de la Basílica de Guadalupe, diciembre 2001-abril de 2002, cat. exp., México D.F., Museo de la Basílica de Guadalupe.

Cuadriello, Jaime (1991): "La propagación de las devociones novohispanas: las Guadalupanas y otras imágenes preferentes". En Discursos en el Arte. XV Coloquio Internacional de Historia del Arte, México, pp. 268-288.

Cuesta, Ángel (1995): Historia de los Agustinos Recoletos. Volumen I. Desde los orígenes hasta el siglo XIX, Madrid, editorial Augustinus.

Daly, Aedan (1971): Sant'Isidoro, Roma, Marietti.

De la Cruz Alcañiz, Cándido, y García Sanchez, Jorge (2009), "L’accademia romana di Francisco Preciado de la Vega in Piazza Barberini e gli artisti spagnoli del Settecento". En Bollettino d'Arte, 1, pp. 91-102.

Díaz Moreno, Félix, y Lopezosa Aparicio, Concepción (1989): "Nuevas aportaciones sobre el desaparecido convento de Agustinos Recoletos de Madrid". En Anales de Historia del Arte, 9, pp. 181-206.

Faldi, I. (1958): “L'allegoria della «vita umana» di Francesco Grassia”. En Paragone, IX, 99, pp. 36-40.

Fernández Alfonso, Justo (1995): “España en Santa María la Mayor”. En Anthologica Annua, 42, pp. 799-810.

Forte, S. L. , (1963): "Il domenicano Giuseppe Paglia, architetto siciliano a Roma". En Archivium Fratrum Praedicatorum, 33, 1963, pp. 281-409.

Gigli, Elena (1997): "Piazza di Spagna. Apparati tra Francia e Spagna”. En Fagiolo dell'Arco, Marcello (dir.), La festa a Roma dal Rinascimento al 1870, Roma, Umberto Allemandi, pp. 202-211.

Gotor, Miguel (2007): "Le canonizazioni dei santi spagnoli nella Roma barocca". En Hernando, Carlos José, (coord.), Roma y España. Un crisol de la cultura europea en la Edad Moderna, Madrid, Seacex, pp. 621-639.

Gutiérrez, Constancio (1955): "España por el dogma de la Inmaculada: la embajada a Roma de 1659 y la bula "Sollicitudo" de Alejandro VII". En Miscelánea Comillas, XXIV, pp. 7-480.

Iturbe, Antonio (2007): "Patrimonio artístico de tres conventos agustinos en Madrid antes y después de la desamortización de Mendizábal”. En Campos y Fernández de Sevilla, Francisco Javier (eds.), La desamortización: el expolio del patrimonio artístico y cultural de la Iglesia en España, El Escorial, Ediciones Escurialenses, pp. 335-368.

Laurain-Portemer, M. (1968): “Mazarin, Benedetti et l'Escalier de la Trinité des Monts”. En Gazatte des Beaux-Arts, 72, pp. 273-294.

León, Gabriel de (1663): Compendio del origen de la esclarecida y milagrosa imagen de N.S. de Copacabana patrona del Peru, Madrid, Pablo de Val.

Lopresti, L. (1927): “Tre sculture di un siciliano a Roma”. En L'Arte, XXX, pp. 89-96.

Lotz, Wolfgang (1969): "Die Spanische Treppe. Architektur als Mittel der Diplomatie”. En Römisches Jahrbuch für Kunstgeschichte, 12, pp. 39-94.

Marder, T.A. (1980): “Bernini and Benedetti at Trinità dei Monti”. En Art Bulletin, LXII, 2, pp. 286-289.

Marraci, Ippolito (1656): De diua virgine, Copacauana, in Peruano noui mundi regno celeberrima. Liber vnus, Roma, apud haeredi Colinii.

Meleo, Mascia, y Curzietti, Jacopo (2006): “Alcune novità documentarie sullo scultore Francesco Grassia". En Annali dell'Associazione Nomentana, 7, pp. 77-87.

Arch. esp. arte, LXXXVIII, 349, ENERO-MARZO 2015, 69-84

ISSN: 0004-0428, eISSN: 1988-8511, doi: 10.3989/aearte.2015.05 
Millán, Cleto (1987): “Colegio de San Ildefonso: cincuenta años de servicio a la orden”. En Recollectio, 10, pp. 119-149.

Molanus, Johannes (1570): De picturis et imaginibus sacris, Lovaina, H. Wellaeus.

Pou y Martí, J. M. (1931-1933): "Embajadas de Felipe III a Roma pidiendo la definición de la Inmaculada Concepción de María". En Archivo Ibero Americano, 34, 1931, pp. 371-417, 508-534; 35, 1932, pp. $72-$ 88, 424-434; 36, 1933, pp. 5-48.

Pulcini, Walter (1957): Le prodigiose rose del Tepeyac : cenni storici sulle apparizioni di Nostra Signora di Guadalupe e sulla devozione nel Messico e nel mondo. Notizie particolari su Arsoli. Le immagini della Vergine di Guadalupe a Roma e in Italia, Tivoli, De Rossi.

Ramos Gavilán, Alonso (1976): Historia de Nuestra Señora de Copacabana, (2 $2^{a}$ ed. completa, según la impresión príncipe de 1621), La Paz, Academia Boliviana de la Historia.

Relación de las fiestas que la Universidad de Salamanca celebró desde 27 hasta 31 de octubre del año de 1618, al juramento del nuevo estatuto, hecho en 2 de mayo del dicho año, de que todos los graduados defenderán la pura y limpia Concepción de la Virgen Nuestra Señora, concebida sin mancha de pecado original. Ordenada por mandado y comisión de la misma Universidad en su claustro pleno. Con licencia del ordinario, Salamanca, en la imprenta de Antonia Ramírez, 1618.

Ringbom, S. (1962): "Maria in sole and the Virgin of the Rosary". En Journal of the Warburg and Courtauld Institutes, 25 (3/4), pp. 326-330.

Rípodas Ardanaz, Daisy (1995): "Presencia de América en la España del seiscientos: el culto a la Virgen de Copacabana”. En Páginas sobre hispanoamérica colonial. Sociedad y cultura, 2, pp. 47-78.

Salles-Reese, Verónica (2008): De Viracocha a la Virgen de Copacabana: representación de lo sagrado en el lago Titicaca, La Paz, Plural Editores.

San José, fray F. de (1743): Historia universal de la primitiva imagen de Nuestra Señora de Guadalupe, Madrid, Imprenta de Antonio Marín.

Santa María, Antonio de (1682): España triunfante y la Iglesia laureada en todo el globo de el mundo por el patrocinio de Maria Santissima en España, Madrid, por Julián de Paredes.

Santiago Vela, Gregorio de (1913): Ensayo de Biblioteca Iberoamericana de la Orden de San Agustín, t. I, Madrid, Imprenta del asilo de huérfanos del Sagrado Corazón de Jesús.

Sebastián, Santiago (1976): "El tema de la Virgen de Guadalupe en Juan Correa". En Anales del Instituto de Investigaciones Estéticas, 46, pp. 65-66.

Sebastían, Santiago (1981): "Simbolismo mariano de la Letanía Lauretana". En Contrarreforma y Barroco, Madrid, Alianza, pp. 207-215.

Stratton, S. (1994): The Inmaculate Conception in Spanish Art, Nueva York-Londres, Cambridge University Press (traducción española en "La Inmaculada Concepción en el arte español". En Cuadernos de arte e iconografía, I, 2, 1988, pp. 3-126).

Tancioni, G. (1989): "Intorno a quattro disegni di Francesco Ferrari per S. Francesca Romana". En L'architettura da Clemente XI a Benedetto XIV, Roma, Multigrafica Editrice, pp. 33-48.

Tormo y Monzó, Elías (1942): Monumentos de españoles en Roma, y de portugueses e hispano-americanos, Ministerio de Asuntos Exteriores y Relaciones Culturales, Madrid, Ministerio de Asuntos Exteriores y Relaciones Culturales.

Vargas Lugo, Elisa (1987): "Iconología guadalupana". En Imágenes guadalupanas, cuatro siglos, Centro Cultural de Arte Contemporáneo, ciudad de México, Noviembre 1987-Marzo 1988, cat. exp., México, pp. $57-61$.

Vetter, M. (1958-59): "Mulier amicta sole und mater Salvatoris". En Münchner Jahrbuch der bildenden Kunst, 3, pp. 32-71.

Vichi, V. (1961): "Francesco Ferrari". En Bollettino dell'Unione storia e arte, IV, 5, pp. 8-11.

Vichi, V. (1966): "Ss. Ildefonso e Tommaso di Villanova”. En Bollettino dell'Unione storia e arte, IX, 7, p. 34.

VV. AA. (1996): La scalinata di Trinità dei Monti, Milán, Vallardi.

Fecha de recepción: 20-I-2014

Fecha de aceptación: 13-V-2014

Arch. esp. arte, LXXXVIII, 349, ENERO-MARZO 2015, 69-84 ISSN: 0004-0428, eISSN: 1988-8511, doi: 10.3989/aearte.2015.05 